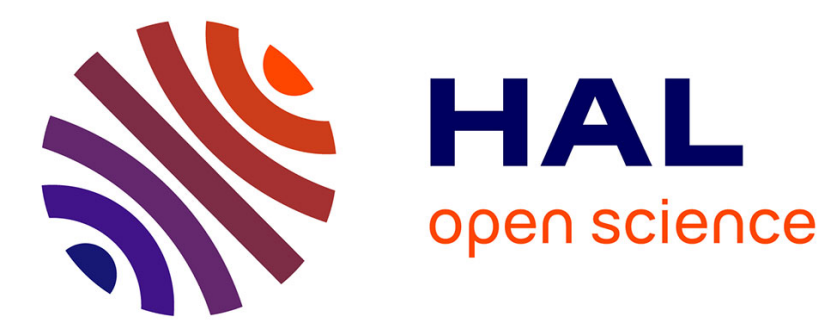

\title{
An x-ray study of palladium hydrides up to 100 GPa: Synthesis and isotopic effects
}

Bastien Guigue, Grégory Geneste, Brigitte C. Leridon, Paul Loubeyre

\section{To cite this version:}

Bastien Guigue, Grégory Geneste, Brigitte C. Leridon, Paul Loubeyre. An x-ray study of palladium hydrides up to 100 GPa: Synthesis and isotopic effects. Journal of Applied Physics, 2020, 127 (7), pp.075901. 10.1063/1.5138697 . hal-03024503

\section{HAL Id: hal-03024503 https://hal.science/hal-03024503}

Submitted on 11 Dec 2020

HAL is a multi-disciplinary open access archive for the deposit and dissemination of scientific research documents, whether they are published or not. The documents may come from teaching and research institutions in France or abroad, or from public or private research centers.
L'archive ouverte pluridisciplinaire HAL, est destinée au dépôt et à la diffusion de documents scientifiques de niveau recherche, publiés ou non, émanant des établissements d'enseignement et de recherche français ou étrangers, des laboratoires publics ou privés. 


\title{
An x-ray study of palladium hydrides up to $100 \mathrm{GPa}$ : Synthesis and isotopic effects.
}

\author{
Bastien Guigue, ${ }^{1,2}$ Grégory Geneste ${ }^{2}$ Brigitte Leridon, ${ }^{1}$ and Paul Loubeyre ${ }^{2, \text { a) }}$ \\ 1) LPEM, ESPCI Paris, PSL Research University, CNRS, Sorbonne Université, 75005 Paris, \\ France \\ ${ }^{2)} C E A$, DAM, DIF, F-91297 Arpajon, France
}

(Dated: 10 December 2020)

The stable forms of palladium hydrides up to $100 \mathrm{GPa}$ were investigated using the direct reaction of palladium with hydrogen (deuterium) in a laser-heated diamond anvil cell. The structure and volume of $\operatorname{PdH}(\mathrm{D})_{x}$ were measured using synchrotron $\mathrm{x}$-ray diffraction. The $\mathrm{Pd}$ atoms remain on a $f c c$ lattice. The stoichiometry of the hydride is inferred from the volume expansion due to the hydrogen solubility in the Pd lattice. No evidence for hydrogen to palladium ratio greater than 1 is observed for both isotopes. An inverse isotope effect on the formation enthalpy of the stoichiometric $\mathrm{Pd}$ hydride is disclosed by measuring the equilibrium formation pressure of $\mathrm{PdH}$ and of $\mathrm{PdD}, 1.9 \mathrm{GPa}$ and $2.7 \mathrm{GPa}$ respectively. An isotopic shift between the compression curves of $\mathrm{PdH}$ and of $\mathrm{PdD}$ is also measured, in good agreement with $a b$ initio calculations quantifying the contribution of the hydrogen zero-point vibrational energy.

\section{INTRODUCTION}

$\mathrm{PdH}$ is a prototypical metallic hydride. Since its discovery in $1866^{1}$, it has been extensively studied for its unusual properties and its applications. $\mathrm{PdH}$ is probably the best known superconducting hydride. Incorporation of hydrogen in the $\mathrm{Pd}$ lattice induces superconductivity, with a critical temperature $\left(T_{C}\right)$ as high as $9 \mathrm{~K}$ for $\mathrm{PdH}^{2}$. A peculiar aspect of the $\mathrm{PdH}$ superconductivity is the existence of an inverse isotope effect, with a $T_{C}$ of $11 \mathrm{~K}$ in $\mathrm{PdD}^{3}$. Only recently, the explanation of this effect was quantitatively given by including anharmonic phonons contributions 4 . Palladium is one of the few elements that readily absorb hydrogen, forming $\mathrm{PdH}_{x}$ with $x \sim 0.7$ under 1 atm pressure ${ }^{5}$, and so it is used as a safe storage of large tritium amounts in the form of Pd-tritides 6 .

The absorption of hydrogen by palladium forms two distinct phases: a solid solution $\alpha$-phase at lower hydrogen concentrations and a lattice expanded $\beta$-phase at higher hydrogen concentrations ${ }^{7}$. In the P-T-x space the boundary line between the $\alpha$ and $\beta$ phases ends with a critical point, reported to be $\left(2.4 \mathrm{MPa}, 273^{\circ} \mathrm{C}\right)$ in the $\mathrm{Pd}-\mathrm{H}_{2}$ system, and $(30.9 \mathrm{MPa}$, $283^{\circ} \mathrm{C}$ ) in the $\mathrm{Pd}-\mathrm{D}_{2}$ system 7 . For both the $\alpha$ and $\beta$ phases, hydrogen is assumed to occupy octahedral $(\mathrm{O})$ interstitial sites of the Pd $f c c$ lattice. While for $x>0.7$ both neutron experiments on metastable samples and first principle calculations indicate that only the $(\mathrm{O})$ sites are occupied $\sqrt[489]{ }$, on the other hand neutron measurements showed a significant tetrahedral (T) interstitial sites occupancy for $x \sim 0.6^{10 \mid 11}$. Thereof, the T-occupancy, under certain P-T-x conditions, cannot be ruled out. Indeed, metastable phases at ambient pressure, related to both $(\mathrm{O})$ and $(\mathrm{T})$ sites occupancies and to a hydrogen-topalladium $(\mathrm{H}: \mathrm{Pd})$ ratio larger than 1 , have been invoked to explain claimed extraordinary properties of palladium hydride, such as a high temperature superconductivity with a $T_{C}$ at least about $50 \mathrm{~K}^{12}$ or even higher ${ }^{13}$ and an anomalous release of energy interpreted as a cold fusion process 14 . The suspected

\footnotetext{
a)paul.loubeyre@cea.fr
}

large amount of hydrogen in Pd could be achieved either by electrochemical loading or by rapidly quenching a high temperature metastable phase. However, both claims remain unconfirmed. The possibility to create highly H loaded Pd hydrides is thus worth exploring.

The first aim of the present study is to investigate the existence of overstoichiometric Pd hydride by applying high hydrogen pressure. Near ambient pressure, the $\beta$-phase is limited to a stoichiometry of 0.77 . Further hydrogen absorption into the $\beta$-phase requires an increase of the hydrogen pressure ${ }^{15}$. The equilibrium hydrogen pressures for the formation of the stoichiometric $\mathrm{PdH}$ and $\mathrm{PdD}$, estimated in the GPa range, have still not been precisely determined. Some experimental results suggest that by compressing the $\mathrm{Pd}-\mathrm{H}$ system, hydrides with $\mathrm{H}: \mathrm{Pd}$ ratio greater than 1 might be obtained and at sufficiently high pressure the Pd dihydride could be stabilized. By putting Pd under a $5 \mathrm{GPa}$ hydrogen pressure at $700^{\circ} \mathrm{C}$, a stoichiometry of 1.33 was reported in the form of a vacancy-ordered structure 16 . That is the highest documented $\mathrm{H}: \mathrm{Pd}$ ratio. Also, over the past decade, a novel view on the chemistry of hydrogen with metals has emerged, with the discovery of the dramatic increase of hydrogen solubility in metals under pressure. An evolution from interstitial hydrides to compounds, having unusual hydrogen-to-metal ratios, is observed under pressure. Transition metal hydrides usually have an hydrogen-to-metal ratio close to 1 , with hydrogen in the interstitial sites of the close-packed lattice. Until recently, at ambient pressure, dihydride configurations were only known for five transition metals from groups IV and V (Ti, Zr, Hf, $\mathrm{V}$ and $\mathrm{Nb}) \underline{5}$. By compressing metals embedded in hydrogen using a diamond anvil cell, other dihydrides were discovered: $\mathrm{TaH}_{2}$ at $5 \mathrm{GPa}^{17}, \mathrm{RhH}_{2}$ at $8 \mathrm{GPa}^{18}, \mathrm{FeH}_{2}$ at $67 \mathrm{GPa}^{19}$ and $\mathrm{CrH}_{2}$ at $30 \mathrm{GPa}^{20}$. In particular, with the discovery of $\mathrm{RhH}_{2} \frac{18}{20}$ and $\mathrm{IrH}_{3} \sqrt{21}$, respectively the first dihydride and trihydride of the platinum group, it seems promising to look for the formation of $\mathrm{PdH}_{2}$ under pressure. In a recent study limited to 20 $\mathrm{GPa}$, the formation of a Pd-Rh dihydride was observed, for $\mathrm{Rh}$ rich alloys 22 . For Pd-rich alloys, it was suspected that a fraction of $\mathrm{H}$ atoms could also occupy (T) sites, that could lead to extra solubility of $\mathrm{H}$ in $\mathrm{Pd}$ and a $\mathrm{H}: \mathrm{P}$ ratio over 1 above 20 
$\mathrm{GP}^{22}$. PdH was observed to remain the stable phase in a recent compression experiment of Pd in hydrogen to $100 \mathrm{GP}^{\sqrt{23}}$. However, in this experiment, no laser-heating of the sample was coupled to high pressure so as to overcome a possible kinetic barrier for the diffusion of $\mathrm{H}$ atoms in (T) sites. The present study explores the formation of palladium hydrides under pressures of hydrogen up to $100 \mathrm{GPa}$. Laser-heating of the Pd samples embedded in hydrogen eliminates any possible kinetic hindrance for the $\mathrm{H}$ diffusion in $\mathrm{Pd}$.

The second aim of this study is to quantify the isotopic difference between the compression curves and formation pressures of palladium hydride and deuteride. Are the isotopic effects normal or inverse as for the superconductivity temperature?

\section{METHODS}

The sample preparation and the synchrotron $\mathrm{x}$-ray diffraction measurements were similar to those used in our previous studies on the synthesis of $\mathrm{Fe}, \mathrm{S}$ and $\mathrm{Cr}$ hydrides at high pressure 1920124 . In total, six pressure runs were performed on palladium samples embedded in different pressure transmitting media in the diamond anvil cell: 1 run using neon to measure a reference compression curve, 3 runs using hydrogen and 2 runs using deuterium. Two diamond tip diameters, $300 \mu \mathrm{m}$ and $150 \mu \mathrm{m}$, were used to go up to and above 60 GPa respectively. Samples were confined in rhenium gaskets, with a gold coating of about 700 Atto prevent the loss of hydrogen by diffusion. The gases were loaded in the diamond anvil cell (DAC) under $140 \mathrm{MPa}$. As shown in Fig. 1, the palladium flake was always surrounded by a much larger volume of hydrogen or deuterium, to be able to synthesize the hydride with the highest stoichiometry stable on the convex hull at a given pressure. Pressure was measured either using the equation of state of a small marble of gold ${ }^{25}$ or using the luminescence of a ruby $\sqrt{26}$, loaded close to the Pd sample. The ruby gauge was favored below $40 \mathrm{GPa}$ to determine pressure with good accuracy. The random uncertainty in pressure is of 0.05 GPa with the ruby gauge, and about $2 \%$ with the gold gauge. The systematic uncertainty, due to the calibration of the pressure scales, should increase these error bars by about a factor 2. For the isotopic shift determinations shown below, which are based on a relative pressure shift at a given volume, only the random uncertainty is limiting the data accuracy. X-ray diffraction (XRD) data were collected at the ID27 beamline of the ESRF with a wavelength of $0.3738 \AA$. The XRD data were then analyzed using DIOPTAS $S^{27}$, the FULLPROF software suite ${ }^{28}$ and the XRDA suite ${ }^{29}$.The uncertainty in volume is $\pm 0.04 \AA^{3}$ /formula unit (f.u.). For each run, the sample was heated at different pressures, as indicated in Fig. 1, to overcome possible kinetic hindrance for the formation of the stable Pd hydride. The temperatures reached during heating were at least about $1300 \mathrm{~K}$ (lower thermoemission visible through the camera setup used), and were sometimes above since the Pd sample could be partially melted.

Calculations were also performed to discuss the mechanism of the isotopic shift on the compression curve of PdH. Ground a)
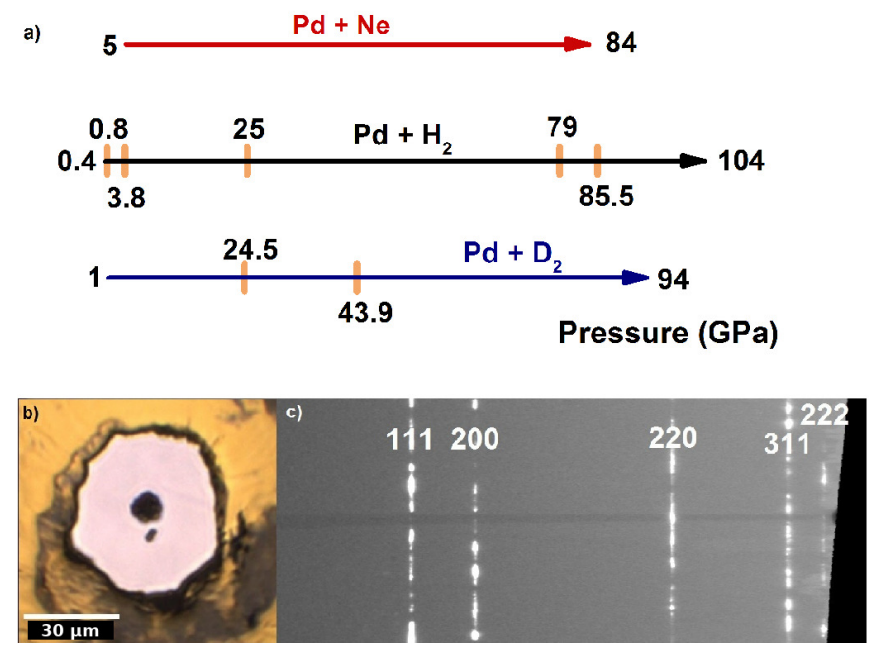

FIG. 1. (a) Schematic representation of the different experimental runs. The pressure domains explored are represented in red for $\mathrm{Pd}+\mathrm{Ne}$ sample, in back for $\mathrm{Pd}+\mathrm{H}_{2}$ (three runs, one with ruby and two with gold as pressure gauges) and in blue for $\mathrm{Pd}+\mathrm{D}_{2}$ (two runs, one with ruby and one with gold as pressure gauges). Laser-heating sequences are represented with yellow vertical ticks, together with the corresponding heating pressure. (b) Photograph of the $10 \mu \mathrm{m} \mathrm{Pd}$ sample with a gold marble, surrounded by solid $\mathrm{H}_{2}$ in excess. The rhenium gasket was coated with a protective 700 Ågold layer. (c) Unrolled recorded XRD image of PdH at $3.8 \mathrm{GPa}$. The spotty character of the XRD pattern explains why its Rietveld refinement could not be satisfactorily performed.
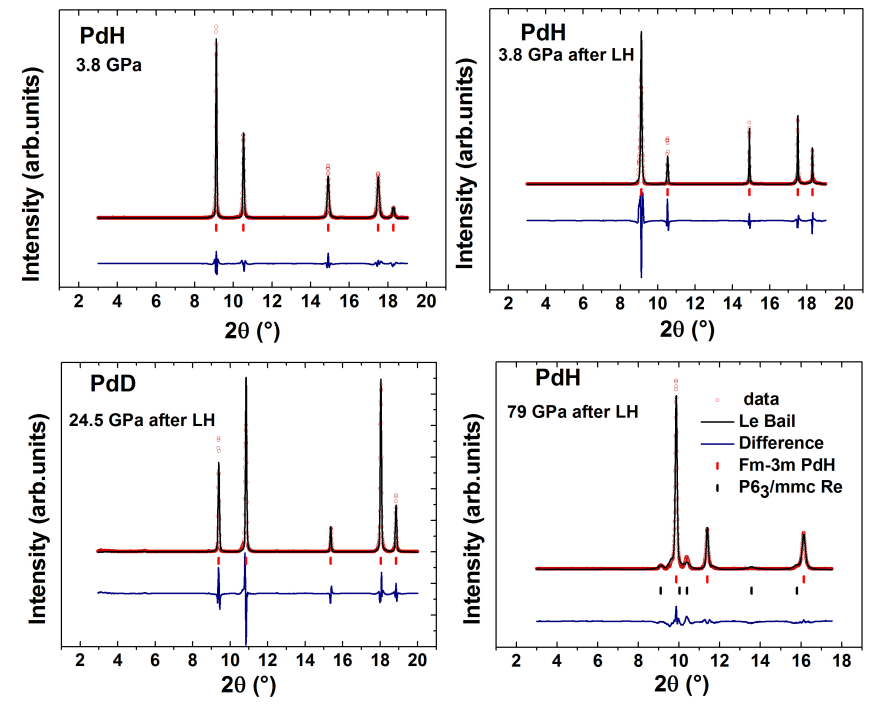

FIG. 2. A selection of XRD patterns: PdH before and after laserheating (LH) at 3.8 GPa; PdD after $\mathrm{LH}$ at $24.5 \mathrm{GPa}$; PdH after $\mathrm{LH}$ at $79 \mathrm{GPa}$. Le Bail refinement (as black line) of the diffraction data (as red dots) is made using a $F m \overline{3} m$ unit cell symmetry (corresponding Bragg peaks are shown as red ticks). The difference between the experiment and the fit is plotted in blue. When present, the rhenium Bragg peaks are shown as black ticks. 


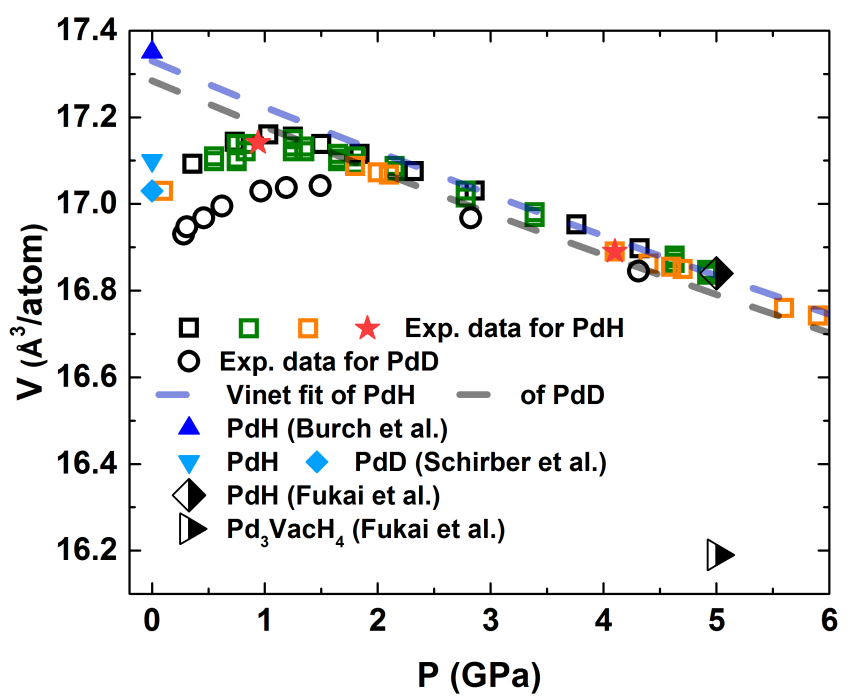

FIG. 3. Volume of Pd hydride (deuteride) in equilibrium with a hydrogen (deuterium) pressure. The squares of different colors indicate the 3 runs performed in hydrogen; the red stars indicate the volume measured after laser-heating in run 3 . The circles indicate the run performed in deuterium. Error bars in pressure and in volume are smaller than the symbols. The triangles indicate the measured volumes at ambient pressure for the metastable stoichiometric hydrides, $\mathrm{PdH}$ and PdD given by Schirber ${ }^{34}$ and Burch 35 . The equilibrium volumes for Pd hydride measured by Fukai at $5 \mathrm{GPa} 22$ are also indicated, both for $\mathrm{PdH}$ and $\mathrm{Pd}_{3} \mathrm{VacH}_{4}$.

state Density Functional Theory (DFT) calculations have been performed using the ABINIT code ${ }^{30}$ in the framework of the Local Density Approximation (LDA). The Projector Augmented Wave (PAW) method ${ }^{31}$ was used with atomic datasets taken from the GBRV table 32 . PdH is simulated in its 2-atom primitive unit cell (space group $F m \overline{3} m$ ), using a $24 \times 24 \times 24$ k-point mesh. The plane-wave cutoff is 35 Hartrees (and 70 Hartrees for the double grid). The phonon modes of $\mathrm{PdH}$ and PdD are computed on a $6 \times 6 \times 6$ q-point mesh, using DensityFunctional Perturbation Theory as implemented in ABINIT 33 .

\section{FORMATION OF PdH AND PdD ONLY}

As shown in Fig. 2, the compounds formed through the spontaneous reaction of $\mathrm{Pd}$ with hydrogen or deuterium, and those after laser-heating, all preserved the cubic structure of $\mathrm{Pd}$. The Rietveld refinement of the structural positions of the $\mathrm{Pd}$ atoms could not be performed because of insufficient quality of the powders. The quality of the powder deteriorated further upon laser-heating, with a tendency to form a multigrains sample. However, for each spectra, a Le Bail refinement confirms that the Pd atoms remained arranged in the cubic unit cell with the $F m \overline{3} m$ symmetry and allowed an accurate volume determination. The hydrogen stoichiometry was estimated using the volumetric expansion caused by the hydrogen (deuterium) insertion inside the palladium lattice.
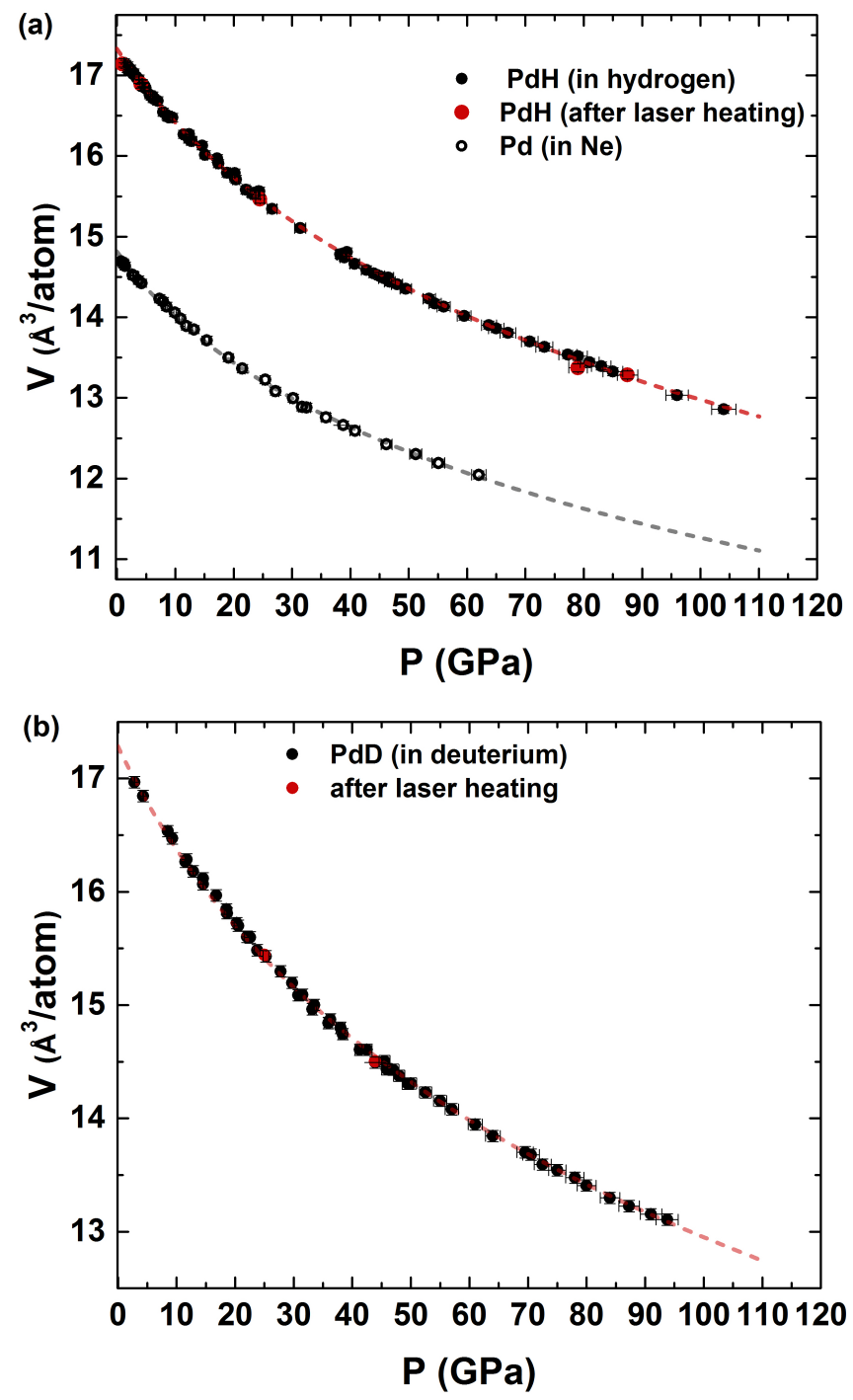

FIG. 4. Compression curves for PdH and PdD (a) Volume vs. pressure for PdH compressed in hydrogen and for Pd in neon. Symbols: black dots and red dots indicate $\mathrm{PdH}$ data after pressure increase at $300 \mathrm{~K}$ and after laser-heating at a given pressure respectively; circles indicate Pd data in Ne. (b) Volume vs. pressure for PdD compressed in deuterium. Symbols: black dots and red dots indicate PdD data after pressure increase at $300 \mathrm{~K}$ and after laser-heating at a given pressure. Error bars are shown, with the uncertainty in pressure being $\pm 2 \%$ and in volume $\pm 0.04 \AA^{3} /$ f.u.

\section{A. Compression curve}

Below $5 \mathrm{GPa}$, as shown in Fig. 3, the volume of $\mathrm{Pd}$ in hydrogen first expands under pressure and then follows a linear compression. The increase in volume of $\mathrm{Pd}$ embedded in hydrogen reflects the loading of hydrogen in the Pd lattice. That evolution was reproducibly followed on the three samples measured and also reversibly obtained upon pressure release. Furthermore, in one run, laser-heating of the sample was performed at several pressures, and the volume of the $\mathrm{Pd}$ hydride then falls exactly on the same curve. That curve hence 
gives the equilibrium volume of Pd embedded in hydrogen at a given pressure. Knowing the volume expansion caused by the insertion of a hydrogen atom inside an $(\mathrm{O})$ site of the $f c c$ lattice of $\mathrm{Pd}$, around $2.5 \AA^{3}$ below $5 \mathrm{GPa}$, the equilibrium volume of the hydride vs. pressure can be analyzed in terms of the evolution of the H:Pd ratio vs. pressure. As a first approximation, we can assume that the $\mathrm{H}: \mathrm{Pd}=1$ ratio is obtained above $3 \mathrm{GPa}$ for Pd compressed in hydrogen and deuterium. However, two differences are clearly seen in Fig. 3 between $\mathrm{Pd}$ in hydrogen and $\mathrm{Pd}$ in deuterium, namely: the volume of $\mathrm{Pd}$ in hydrogen is greater than the volume of $\mathrm{Pd}$ in deuterium above $3 \mathrm{GPa}$ when stoichiometric $\mathrm{PdH}$ and PdD are stable; the pressure to reach the stoichiometric $\mathrm{PdH}$ seems lower than the one for PdD. These two isotope effects are discussed in specific sections below.

The compression curves of $\mathrm{PdH}$ and $\mathrm{PdD}$, embedded in their respective hydrogen isotope pressure medium from 3 $\mathrm{GPa}$ to $100 \mathrm{GPa}$, are plotted in Fig. 4. The data points fall on the same curve, regardless of whether there was previously a laser-heating of the sample. None of the usual signatures of a change of the stoichiometry for hydrides under pressure, i.e. an upward discontinuity of volume or a continuous positive deviation from the compression trend, are oberved here. We can assume that, above $3 \mathrm{GPa}$, stoichiometric $\mathrm{PdH}(\mathrm{PdD})$ is the hydride with the largest $\mathrm{H}$ (D) concentration on the convex hull up to $100 \mathrm{GPa}$ at least. The Vinet equation of state function is used to fit the data points for PdH and PdD. The corresponding parameters are: for $\mathrm{PdH}, V_{0}=17.33(4) \AA^{3}$, $K_{0}=159(3) \mathrm{GPa}$ and $K_{0}^{\prime}=5.6(11)$; for $\mathrm{PdD}, V_{0}=17.29(4)$ $\AA^{3}, K_{0}=159(2) \mathrm{GPa}$ and $K_{0}^{\prime}=5.6(13)$. PdH and PdD have excatly the same isothermal bulk modulus, $K_{0}$, and the same pressure derivative of $K_{0}, K_{0}^{\prime}$. Consequently, PdH and PdD follow exactly the same curve when $V / V_{0}$ is plotted vs. P. A similar behavior was previously measured for the compression curve of $\mathrm{LiH}$ and $\mathrm{LiD}^{36}$. The volumes at ambient pressure for metastable PdH and PdD are $V_{0}=17.33(4) \AA^{3}$ and $V_{0}=17.29(4) \AA^{3}$ respectively. It should be noted that for the estimation of the isotopic shift, systematic uncertainties in the volume determination cancel out, so an isotopic effect can be clearly measured even though its magnitude is of the order of the volumic uncertainty. These two volumes are compared to previous estimations at ambient pressure measured on metastable hydrides, see Fig. 3. The present estimation of $V_{0}$ for $\mathrm{PdH}$ is in good agreement with the value given by Burch $^{35}$. However, it is larger than the value of Shirber ${ }^{34}$. Part of the disagreement with Shirber's volume, which was measured at $77 \mathrm{~K}$, is thus due to thermal expansion. Shirber also measured the isotopic volume difference between metastable $\mathrm{PdH}$ and $\mathrm{PdD}$ at ambient pressure, which is in good agreement with the present determination. The Vinet fits for PdH, PdD and $\mathrm{Pd}$ compression curves at $300 \mathrm{~K}$ are given in Table I]

\begin{tabular}{lccc}
\hline \hline & $V_{0}\left(\AA^{3}\right)$ & $K_{0}(\mathrm{GPa})$ & $K_{0}^{\prime}$ \\
\hline Pd & $14.75(4)$ & $162(2)$ & $6.2(9)$ \\
PdH & $17.33(4)$ & $159(3)$ & $5.6(11)$ \\
PdD & $17.29(4)$ & $159(2)$ & $5.6(13)$ \\
\hline \hline
\end{tabular}

TABLE I. EOS parameters measured from the Vinet fits of the compression curves for $\mathrm{Pd}$ in $\mathrm{Ne}, \mathrm{PdH}$ and $\mathrm{PdD}$.

\section{B. Volume expansion per hydrogen atom}

The compression curve of Pd was measured by embedding $\mathrm{Pd}$ in Ne. The volume-pressure data points are plotted in Fig. 4. The Vinet fit of the Pd compression curve gives the following parameters: $V_{0}=14.75(4) \AA^{3}, K_{0}=162(2) \mathrm{GPa}$ and $K_{0}^{\prime}=6.2(9)$. The volume expansion associated to the transition from $f c c$ Pd to $F m \overline{3} m \mathrm{PdH}$ is given by the subtraction of the volume of pure $\mathrm{Pd}$ from the volume data of $\mathrm{PdH}$ at a given pressure. The results are plotted in Fig. 5. The volume expansion due to $1 \mathrm{H}$ atom per $\mathrm{Pd}$ atom in the $F m \overline{3} m$ lattice is then $2.5 \AA^{3}$ at pressures around $3 \mathrm{GPa}$, which is consistent with the filling of $(\mathrm{O})$ sites. From the synthesis of $\mathrm{RhH}_{2}$, the increase in volume due to an $\mathrm{H}$ occupation of a $(\mathrm{T})$ site was measured around $3.2 \AA^{3}$ under a pressure of a few GPa and it is reasonable to assume that it would be the same value for the occupancy of $(\mathrm{T})$ sites in $\mathrm{Pd}^{22}$. From $3 \mathrm{GPa}$ to $100 \mathrm{GPa}$, the volume expansion per $\mathrm{H}$ atom decreases under pressure, as it was observed for $\mathrm{CrH}$ and $\mathrm{FeH}$ monohydrides $\frac{1920}{2}$, both having a hcp lattice. The volume per $\mathrm{H}$ atom is slightly bigger in the case of $\mathrm{PdH}$. Two previous measurements of the volume of $\mathrm{PdH}$ under pressure give experimental values of the volume expansion per $\mathrm{H}$ atom bounding the present data, the determination of Brownsberger ${ }^{23}$ above and the one of Kuzovnikov below 22 . The calculated volume expansion per hydrogen atom under pressure is in good agreement with the present determination from $3 \mathrm{GPa}$ to $100 \mathrm{GPa}$. The $\mathrm{H}$ or $\mathrm{D}$ atoms are thus likely to fill the $(\mathrm{O})$ sites of Pd up to $100 \mathrm{GPa}$. The filling of the $(\mathrm{T})$ sites, even partially, was expected above $20 \mathrm{GPa}$ from the observation of dihydrides in palladium-rhodium alloys 22 . As theoretically shown by Errea 37 , anharmonic effects play a stabilizing role for $\mathrm{H}$ atoms in $(\mathrm{O})$ sites, so populating $(\mathrm{T})$ sites could be favored in PdD. Yet, that is not observed.

Finally, it is interesting to note that the possibility to reach $\mathrm{H}: \mathrm{Pd}$ ratio greater than 1 by rapidly cooling the Pd hydride after loading it with hydrogen at elevated temperature has already been reported twice. Under $10 \mathrm{MPa}$ hydrogen pressure and temperature around $500^{\circ} \mathrm{C}$ and at $5 \mathrm{GPa}$ under $700^{\circ} \mathrm{C}$ for a few hours ${ }^{16}$. In the latter case, the superabundant vacancies $\mathrm{Pd}$ hydride, $\mathrm{Pd}_{3} \mathrm{VacH}_{4}$, was well characterized. As plotted in Fig. 2. the $\mathrm{Pd}_{3} \mathrm{VacH}_{4}$ compound has a much smaller volume/Pd atom than $\mathrm{PdH}$. By laser-heating the Pd sample in hydrogen above $1300 \mathrm{~K}$ and rapidly quenching it at ambient temperature by turning off the laser, no formation of an overstoichiometric hydride could be observed over the pressure range investigated from $0.5 \mathrm{GPa}$ to $100 \mathrm{GPa}$. Therefore, long resistive heating might be needed to reach metastable forms of Pd hydrides with $\mathrm{H}: \mathrm{Pd}$ ratio larger than 1, such as implemented for the synthesis of superabundant vacancies $\mathrm{Pd}_{3} \mathrm{VacH}_{4}$. 


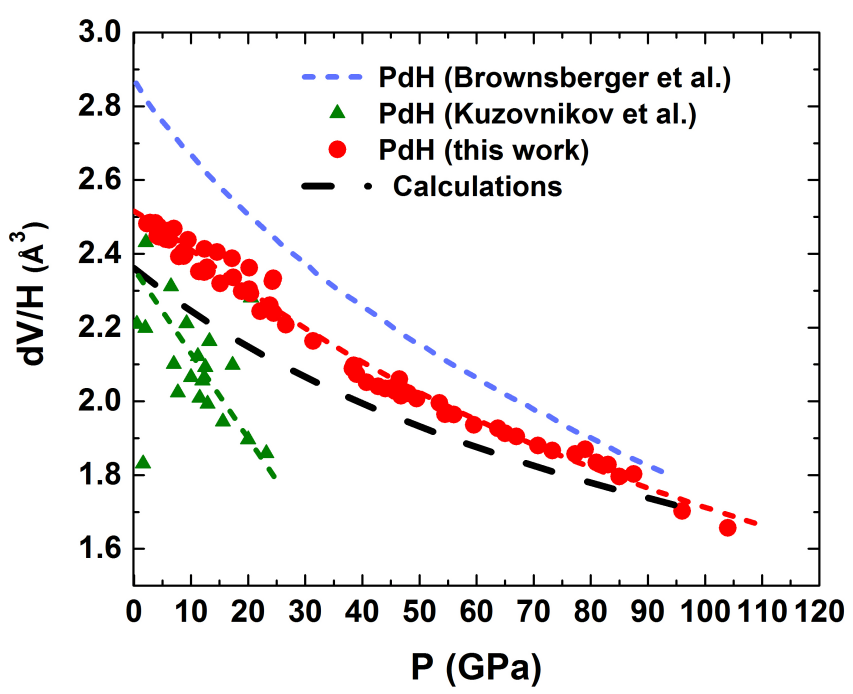

FIG. 5. Volume expansion per $\mathrm{H}$ atom for $\mathrm{PdH}$ as a function of pressure. Experimental data points are plotted as red dots. The black dashed line is the $a b$ initio calculation. Previous determinations from ref. ${ }^{[23}$ and ref. ${ }^{[22}$ are plotted as blue dashed line and green triangles respectively.

\section{ISOTOPIC SHIFT}

\section{A. Formation pressure}

The non-monotonic evolution under pressure of the volume of Pd embedded in excess hydrogen up to $5 \mathrm{GPa}$, as plotted in Fig. 3, can be analyzed as the variation under pressure of the $\mathrm{H}$ concentration in $\mathrm{Pd}$. For a quantitative analysis of the change of the H:Pd ratio with pressure, the volume difference between the present measurements and the expected volume of the stoichiometric hydride and deuteride (as given by the fits of the compression curves of $\mathrm{PdH}$ and $\mathrm{PdD}$ extrapolated below $3 \mathrm{GPa}$ ) is divided by the volume expansion per hydrogen atom below $3 \mathrm{GPa}\left(2.5 \pm 0.1 \AA^{3}\right.$, as measured here and in very good agreement with accepted literature value ${ }^{5}$ ). The isotopic difference between the volume expansion due to the filling of $(\mathrm{O})$ sites of bulk $\mathrm{Pd}$ by $\mathrm{H}$ or $\mathrm{D}$ atoms is here neglected (much smaller than error bars). The evolution of the hydrogen concentration $v s$. pressure is thus plotted in Fig. 6 for $\mathrm{PdH}$ and PdD. That reflects an equilibrium evolution since no scatter was observed between the 3 runs in hydrogen corresponding to different sample sizes and different time scales (from a few minutes to a few hours). Furthermore, laser-heating the sample at $1 \mathrm{GPa}$ and at $4 \mathrm{GPa}$ did not induce any deviation. It is known that at ambient pressure, the $\mathrm{H}(\mathrm{D})$ : $\mathrm{Pd}$ ratio is around 0.7. The lowest pressure investigated here is about $0.3 \mathrm{GPa}$ for which the $\mathrm{H}$ to $\mathrm{Pd}$ ratio is already around 0.9 . A clear isotopic difference is observed, the $\mathrm{D}: \mathrm{Pd}$ ratio being lower than the H:Pd one at a given pressure. Hence, the stoichiometric PdH hydride is stable above $1.9 \mathrm{GPa}$ whereas the PdD hydride is stable above $2.7 \mathrm{GPa}$. Such an isotope effect in the formation of hydrides has already been largely investigated with applications for hydrogen separation or storage.

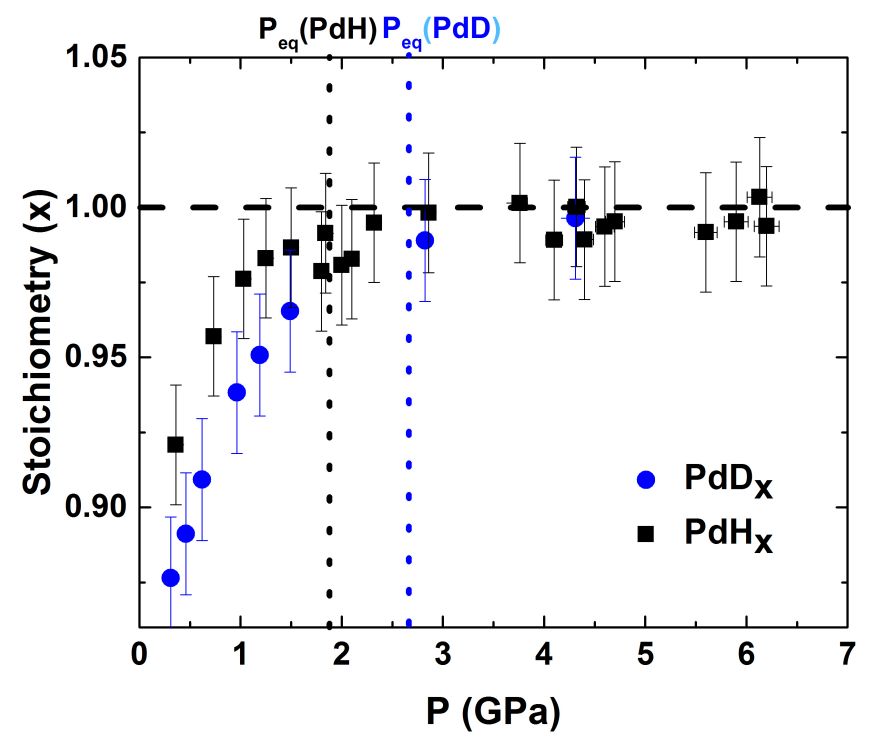

FIG. 6. Isotopic shift on the formation pressure. Evolution of the $\mathrm{H}: \mathrm{Pd}$ ratio and $\mathrm{D}: \mathrm{Pd}$ ratio in palladium hydrides vs. pressure, as black squares and blue dots respectively. The equilibrium pressures of stable stochiometric $\mathrm{PdH}$ and $\mathrm{PdD}$ are indicated by the vertical dotted lines.

It is commonly quantified by comparing the measured formation pressures of the hydride, deuteride and if possible tritide. The lowest equilibrium pressure corresponds to the most stable compound. This normal isotope effect is observed when the tritide is more stable than the deuteride, itself more stable than the hydride; the equilibrium pressure of the deuteride is then lower than the one of the hydride. Here, we thus observed an inverse isotope effect. The isotopic effect should be canceled when the hydrogen atom contribution to the hydride's Zero-Point Energy (ZPE) is equal to half of the $\mathrm{H}_{2}$ molecule's $\mathrm{ZPE}{ }^{38139}$.

\section{B. Compression curve}

Although $\mathrm{PdH}$ and $\mathrm{PdD}$ have identical values for $K_{0}$ and $K_{0}^{\prime}$, the difference in the values of the ambient pressure $V_{0}$ induces an isotopic shift for the volume at a given pressure. The volume of $\mathrm{PdH}$ is greater than the one of PdD from ambient pressure up to $100 \mathrm{GPa}$, or equivalently, for a given volume the pressure of $\mathrm{PdH}$ is greater than the one of $\mathrm{PdD}$, and increasing with pressure from $0.4 \mathrm{GPa}$ near $3 \mathrm{GPa}$ to $1.2 \mathrm{GPa}$ near 80 $\mathrm{GPa}$. This result is quantitatively in agreement with a similar measurements performed on lithium hydride and deuteride 36 . This is at odds with the findings of Brownsberger ${ }^{23}$, reporting a crossing between the $\mathrm{PdH}$ and $\mathrm{PdD}$ compression curves around $100 \mathrm{GPa}$. The need for small error bars on the data points to disclose the isotopic shift is illustrated in Fig. 7. Furthermore, the random uncertainty is here statistically reduced by having a large number of data points.

The isotopic shift on the EOS of palladium hydride is due to the ZPE of the hydrogen atom. Being larger for $\mathrm{H}$ than for 


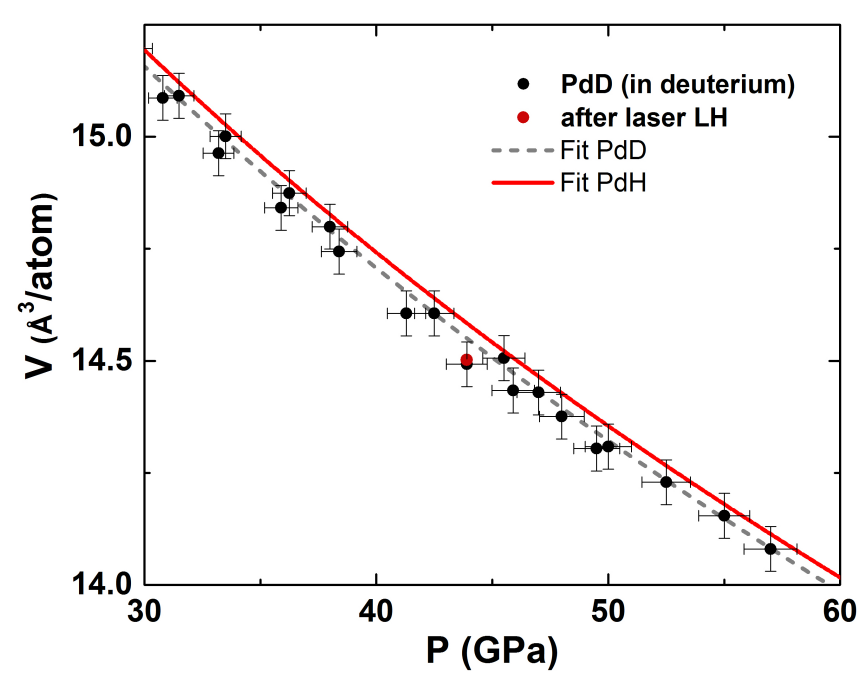

FIG. 7. Isotopic shift on the compression curves of PdH and PdD in between 30 and $60 \mathrm{GPa}$. The Vinet fits of the EOS of PdH and PdD are plotted as full red line and black dash line respectively. The data points for $\mathrm{PdD}$ are shown with their error bars.

$\mathrm{D}$, PdH has a larger lattice parameter than PdD at a given pressure. A normal isotope effect is observed here. The ZPE contribution was estimated from the calculation of phonon spectrum in $\mathrm{PdH}$ and PdD under pressure. By performing calculations within the LDA approximation, we somehow circumvent the instability problem of $\mathrm{PdH}$ at low pressure if using the GGA-PBE functional and for which the renormalization of the phonon spectra by anharmonicity is necessary $\sqrt{37}$. Anharmonicity contributions are not taken into account in our calculation, thus certainly less rigorous and semi-quantitative. However, as shown below, the isotopic shift is based on the volume derivative of the phonon frequencies and so the derivative of the anharmonicity contribution should be of a second order effect. The evolution of the phonon structure of $\mathrm{PdH}$ between $3 \mathrm{GPa}$ and $30 \mathrm{GPa}$ is shown in Fig. 8 The modes associated to $H(D)$ motion are well separated from those associated with Pd motion, except at low pressure where the two partial vibrational densities of states (for Pd and for $\mathrm{H}(\mathrm{D})$ ) begin to overlap. This overlap occurs around $10-15 \mathrm{GPa}$ in $\mathrm{PdD}$ and around $0-3 \mathrm{GPa}$ in $\mathrm{PdH}$. As the pressure is increased, the branches associated to $H(D)$ are rather rigidly shifted to higher wave numbers, while those associated to Pd are almost unchanged with pressure. The volume-dependence of the hydrogen of the hydrogen projected phonon energies suggests that hydrogen zero-point motions should contribute to the pressure, offering an explanation for the isotope effect which is observed on the experimental EOS. In order to estimate this contribution, we set up a simple model, in which $\mathrm{H}$ motion is replaced by that of a single 3D-Einstein oscillator, with pulsation $\omega_{E} . \omega_{E}$ is determined by averaging the phonon density of states projected on H/D. The evolution of the effective Einstein frequency $v s$. the unit cell volume is plotted in Fig. 8 A linear evolution is observed, with a slope being larger for $\mathrm{H}$ than for $\mathrm{D}$ by almost the expected $\sqrt{2}$ factor. The isotopic pressure difference at $300 \mathrm{~K}$ and at a given volume is (a) PdH 29.6 GPa

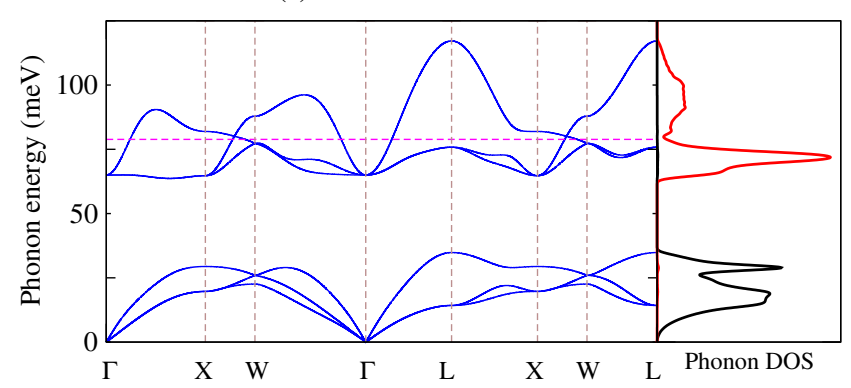

(b) PdH 3.0 GPa

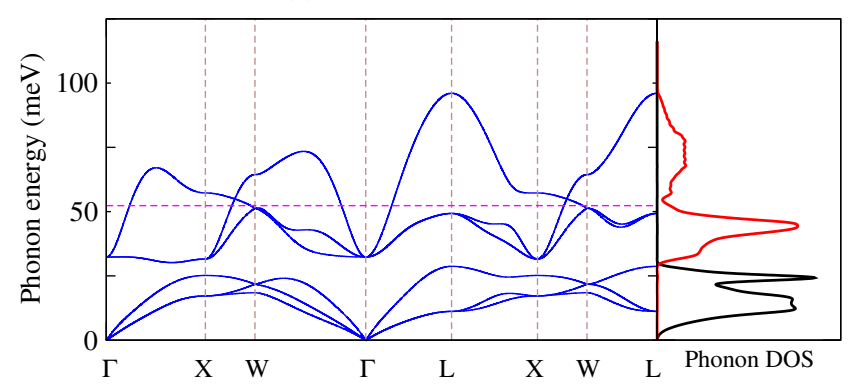

(c) Einstein pulsation

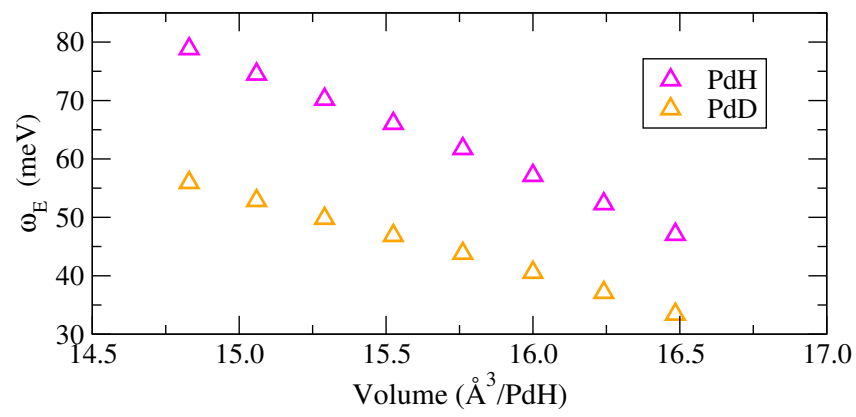

FIG. 8. Phonon bandstructures of PdH at 29.6 GPa (a) and 3.0 GPa (b). The Pd projections are plotted in black, the $\mathrm{H}$ projections in red. (c) Evolution vs. volume of the effective Einstein frequencies corresponding to the $\mathrm{H}$ and $\mathrm{D}$ projections of the phonon bandstructures in $\mathrm{PdH}$ and in $\mathrm{PdD}$, plotted as triangles in the bottom graph. A linear evolution is observed with: $\hbar \omega_{E}(\mathrm{meV})=360.5-18.98 \mathrm{~V}\left(\AA^{3} / \mathrm{PdH}\right)$ for $\mathrm{PdH}$ and $\hbar \omega_{E}(\mathrm{meV})=255.6-13.45 \mathrm{~V}\left(\AA^{3} / \mathrm{PdD}\right)$ for PdD.

then estimated using this linear fit as follows:

$$
\begin{gathered}
\hbar \omega_{E}=K-A V \\
P_{v i b}=-d F / d V \\
=\frac{3}{2} A\left(1+\frac{2}{\exp \left(\hbar \omega_{E} / K_{B} T\right)-1}\right)
\end{gathered}
$$

with $3 / 2 A \sim 4.56$ (resp. 3.23) GPa for $\mathrm{H}$ (resp. D). The calculated isotopic shift in pressure at a given volume is plotted in Fig. 9 and compared to experiment. The agreement is very satisfactory, showing an increase in pressure shift $v s$. pressure. 


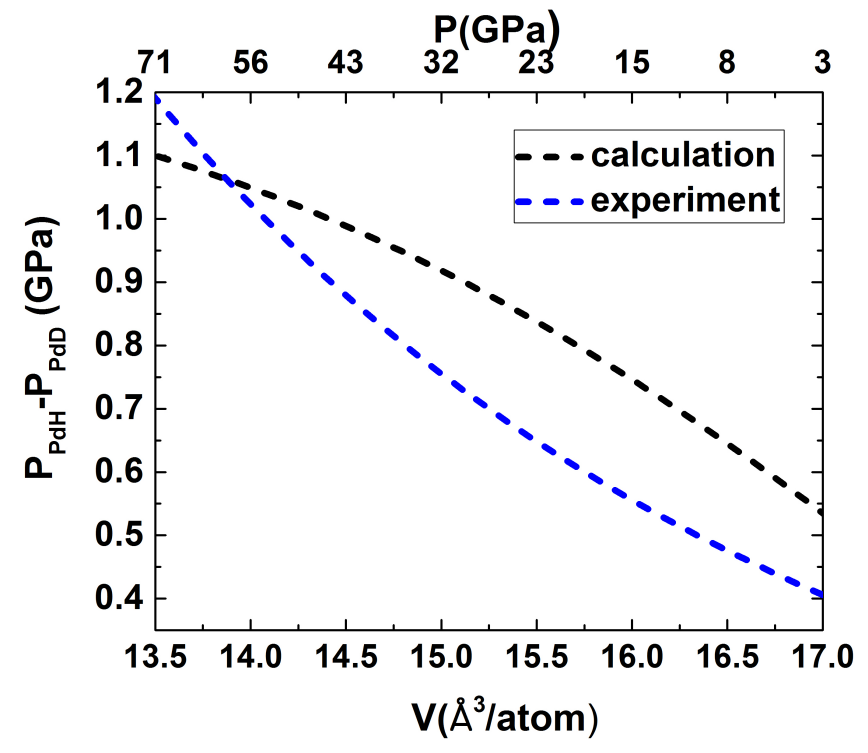

FIG. 9. Isotopic shift on the compression curve of Pd hydride. Experimental determination, as the difference between the Vinet fit of $\mathrm{PdH}$ and PdD EOS, is plotted as a blue dashed line. Calculation, estimated from the Einstein frequency effective modes for $\mathrm{H}$ and $\mathrm{D}$ in $\mathrm{PdH}$ and PdD, is plotted as a black dashed line.

\section{CONCLUSION}

The equilibrium H:Pd (D:Pd) ratio for Pd embedded in excess hydrogen (deuterium) was studied up to $100 \mathrm{GPa}$. No evidence for a H:Pd nor D:Pd ratio larger than 1 was observed. No metastable phases with $\mathrm{H}: \mathrm{Pd}$ ratio larger than 1 could be synthesized by laser-heating Pd in excess hydrogen, even after rapid quenching. The compression curves of $\mathrm{PdH}$ and of $\mathrm{PdD}$ were measured up to $100 \mathrm{GPa}$. A normal isotopic shift on the compression curve is reported in good agreement with calculations. On the other hand, an inverse isotopic shift is observed for the stability pressure of $\mathrm{PdH}$ and of PdD.

\section{ACKNOWLEDGMENTS}

The authors acknowledge the European Synchrotron Radiation Facility for provision of synchrotron radiation on beam line ID27. More particularly, we would like to thank M. Mezouar, G. Garbarino and V. Svitlyk for their precious help with the XRD experiments.

\footnotetext{
${ }^{1}$ T. Graham, "XVIII. On the absorption and dialytic separation of gases by colloid septa," Philosophical Transactions of the Royal Society of London 156, 399-439 (1866) https://royalsocietypublishing.org/doi/pdf/10.1098/rstl.1866.0018

${ }^{2} \mathrm{~T}$. Skoskiewicz, "Superconductivity in the palladiumhydrogen and palladium-nickel-hydrogen systems,"

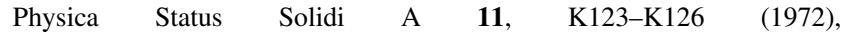
https://onlinelibrary.wiley.com/doi/pdf/10.1002/pssa.2210110253

${ }^{3}$ H. Hemmes, A. Driessen, R. Griessen, and M. Gupta, "Isotope effects and pressure dependence of the $T_{C}$ of superconducting stoichiometric $\mathrm{PdH}$ and PdD synthesized and measured in a diamond anvil cell," Phys. Rev. B 39, 4110-4118 (1989)
}

${ }^{4}$ I. Errea, M. Calandra, and F. Mauri, "First-Principles Theory of Anharmonicity and the Inverse Isotope Effect in Superconducting PalladiumHydride Compounds," Phys. Rev. Lett. 111, 177002 (2013)

${ }^{5}$ Y. Fukai, The Metal-Hydrogen System: Basic Bulk Properties (Springer, 2005).

${ }^{6}$ R. C. J. Bowman, R. S. Carlson, and R. J. De Sando, "Characterization of metal tritides for the transport, storage, and disposal of tritium," in Trans. Am. Nucl. Soc.; (United States) (1976).

${ }^{7}$ F. D. Manchester, A. San-Martin, and J. M. Pitre, "The H-Pd (hydrogenpalladium) System," Journal of Phase Equilibria 15, 62 (1994)

${ }^{8}$ J. E. Worsham, M. Wilkinson, and C. Shull, "Neutron-diffraction observations on the palladium-hydrogen and palladium-deuterium systems," Journal of Physics and Chemistry of Solids 3, 303 (1957)

${ }^{9}$ A. I. Kolesnikov, I. Natkaniec, V. E. Antonov, I. T. Belash, V. K. Fedotov, J. Krawczyk, J. Mayer, and E. G. Ponyatovski, "Neutron spectroscopy of $\mathrm{MnH}_{0.86}, \mathrm{NiH}_{1.05}, \mathrm{PdH}_{0.99}$ and harmonic behaviour of their optical phonons," Physica B: Condensed Matter 174, 257-261 (1991)

${ }^{10}$ G. A. Ferguson, A. I. Schindler, T. Tanaka, and T. Morita, "Neutron Diffraction Study of Temperature-Dependent Properties of Palladium Containing Absorbed Hydrogen,"' Phys. Rev. 137, A483-A487 (1965)

${ }^{11}$ M. P. Pitt and E. M. Gray, "Tetrahedral occupancy in the Pd-D system observed by in situ neutron powder diffraction," Europhysics Letters (EPL) 64, 344-350 (2003)

${ }^{12}$ H. M. Syed, T. J. Gould, C. J. Webb, and E. MacA. Gray, "Superconductivity in palladium hydride and deuteride at 52-61 kelvin," arXiv e-prints , arXiv:1608.01774 (2016), 1608.01774

${ }^{13}$ P. Tripodi, D. Di Gioacchino, and J. D. Vinko, "A review of high temperature superconducting properties of PdH system," International Journal of Modern Physics B 21, 3343-3347 (2007)

${ }^{14}$ C. P. Berlinguette, Y.-M. Chiang, J. N. Munday, T. Schenkel, D. K. Fork, R. Koningstein, and M. D. Trevithick, "Revisiting the cold case of cold fusion," Nature 570, 45-51 (2019)

${ }^{15}$ B. Baranowski, "High Pressure Research on Palladium-Hydrogen Systems," Platinum Metals Rev. 16, 10 (1972).

${ }^{16}$ Y. Fukai and N. Okuma, "Formation of Superabundant Vacancies in Pd Hydride under High Hydrogen Pressures," Phys. Rev. Lett. 73, 1640-1643 (1994)

${ }^{17}$ M. A. Kuzovnikov, M. Tkacz, H. Meng, D. I. Kapustin, and V. I. Kulakov, "High-pressure synthesis of tantalum dihydride," Phys. Rev. B 96, 134120 (2017)

${ }^{18}$ B. Li, Y. Ding, D. Y. Kim, R. Ahuja, G. Zou, and H.-K. Mao, "Rhodium dihydride $\left(\mathrm{RhH}_{2}\right)$ with high volumetric hydrogen density," Proceedings of the National Academy of Sciences 108, 18618 (2011)

${ }^{19}$ C. M. Pépin, A. Dewaele, G. Geneste, P. Loubeyre, and M. Mezouar, "New Iron Hydrides under High Pressure," Phys. Rev. Lett. 113, 265504 (2014)

${ }^{20}$ A. Marizy, G. Geneste, P. Loubeyre, B. Guigue, and G. Garbarino, "Synthesis of bulk chromium hydrides under pressure of up to $120 \mathrm{GPa}$," Phys. Rev. B 97, 184103 (2018)

${ }^{21}$ T. Scheler, M. Marqués, Z. Konôpková, C. L. Guillaume, R. T. Howie, and E. Gregoryanz, "High-Pressure Synthesis and Characterization of Iridium Trihydride," Phys. Rev. Lett. 111, 215503 (2013)

${ }^{22}$ M. A. Kuzovnikov and M. Tkacz, "Dihydride formation in the palladium-rhodium alloys under high hydrogen pressure," International Journal of Hydrogen Energy 42, 340-346 (2017)

${ }^{25} \mathrm{~K}$. Brownsberger, M. Ahart, M. Somayazulu, C. Park, S. A. Gramsch, and R. J. Hemley, "X-ray Diffraction, Lattice Structure, and Equation of State of $\mathrm{PdH}_{x}$ and $\mathrm{PdD}_{x}$ to Megabar Pressures," The Journal of Physical Chemistry C 121, 27327-27331 (2017)

${ }^{24}$ B. Guigue, A. Marizy, and P. Loubeyre, "Direct synthesis of pure $\mathrm{H}_{3} \mathrm{~S}$ from $\mathrm{S}$ and $\mathrm{H}$ elements: No evidence of the cubic superconducting phase up to 160 GPa," Phys. Rev. B 95, 020104 (2017)

${ }^{25} \mathrm{~K}$. Takemura and A. Dewaele, "Isothermal equation of state for gold with a He-pressure medium," Phys. Rev. B 78, 104119 (2008)

${ }^{26} \mathrm{H}$. K. Mao, J. Xu, and P. M. Bell, "Calibration of the ruby pressure gauge to 800 kbar under quasi-hydrostatic conditions," J. Geophys. Res. Sol. Ea. 91, 4673 (1986)

${ }^{2 /} \mathrm{C}$. Prescher and V. B. Prakapenka, "DIOPTAS: a program for reduction of two-dimensional X-ray diffraction data and data exploration," High Pressure Research 35, 223-230 (2015) 
${ }^{28}$ T. Roisnel and J. Rodriguez-Carvajal, "WinPLOTR: a Windows tool for powder diffraction patterns analysis," Proc. EPDIC 7 , 118-123 (2000).

${ }^{29} \mathrm{~S}$. Desgreniers and K. Lagarec, "XRDA: a program for energy-dispersive X-ray diffraction analysis on a PC,"Journal of Applied Crystallography 27, 432-434 (1994)

${ }^{30}$ X. Gonze, F. Jollet, F. Abreu Araujo, D. Adams, B. Amadon, T. Applencourt, C. Audouze, J.-M. Beuken, J. Bieder, A. Bokhanchuk, E. Bousquet, F. Bruneval, D. Caliste, M. Côté, F. Dahm, F. Da Pieve, M. Delaveau, M. Di Gennaro, B. Dorado, C. Espejo, G. Geneste, L. Genovese, A. Gerossier, M. Giantomassi, Y. Gillet, D. R. Hamann, L. He, G. Jomard, J. Laflamme Janssen, S. Le Roux, A. Levitt, A. Lherbier, F. Liu, I. Lukačević, A. Martin, C. Martins, M. J. T. Oliveira, S. Poncé, Y. Pouillon, T. Rangel, G.-M. Rignanese, A. H. Romero, B. Rousseau, O. Rubel, A. A. Shukri, M. Stankovski, M. Torrent, M. J. Van Setten, B. Van Troeye, M. J. Verstraete, D. Waroquiers, J. Wiktor, B. Xu, A. Zhou, and J. W. Zwanziger, "Recent developments in the ABINIT software package," Computer Physics Communications 205, 106-131 (2016)

${ }^{31}$ P. E. Blöchl, "Projector augmented-wave method," Phys. Rev. B 50, 17953 17979 (1994)

${ }^{32}$ K. F. Garrity, J. W. Bennett, K. M. Rabe, and D. Vanderbilt, "Pseudopotentials for high-throughput DFT calculations," Computational Materials Science 81, 446-452 (2014)

${ }^{33} \mathrm{C}$. Audouze, F. Jollet, M. Torrent, and X. Gonze, "Projector augmentedwave approach to density-functional perturbation theory," Phys. Rev. B 73,
$235101(2006)$

${ }^{34}$ J. E. Schirber and B. Morosin, "Lattice constants of $\beta-\mathrm{PdH}_{x}$ and $\beta-\mathrm{PdD}_{x}$ with $x$ near 1.0," Phys. Rev. B 12, 117-118 (1975)

${ }^{35} \mathrm{R}$. Burch, "Theoretical aspects of the absorption of hydrogen by palladium and its alloys. Part 2.-Possible effects of lattice expansion on the solubility of hydrogen in palladium," Trans. Faraday Soc. 66, 749-755 (1970)

${ }^{36}$ P. Loubeyre, R. Le Toullec, M. Hanfland, L. Ulivi, F. Datchi, and D. Hausermann, "Equation of state of $\mathrm{LiH}$ and $\mathrm{LiD}$ from x-ray diffraction to 94 GPa," Phys. Rev. B 57, 10403-10406 (1998)

${ }^{37}$ I. Errea, M. Calandra, and F. Mauri, "Anharmonic free energies and phonon dispersions from the stochastic self-consistent harmonic approximation: Application to platinum and palladium hydrides," Phys. Rev. B 89, 064302 (2014)

${ }^{38}$ N. Bourgeois, J.-C. Crivello, P. Cenedese, V. Paul-Boncour, and J.-M. Joubert, "Vibration analysis of hydrogen, deuterium and tritium in metals: consequences on the isotope effect," Journal of Physics: Condensed Matter 30, 335402 (2018)

${ }^{39}$ N. Bourgeois, J.-C. Crivello, P. Cenedese, and J.-M. Joubert, "Systematic First-Principles Study of Binary Metal Hydrides," ACS Combinatorial Science 19, 513-523 (2017) 